\title{
A Novel Fuzzy Approach for Determining Best Position of Soccer Players
}

\author{
Mohammad Bazmara \\ School of Electrical and Computer Engineering, Shiraz University, Shiraz, Iran \\ E-mail: mohamad.bazmara@g mail.com
}

\begin{abstract}
A combination of various fuzzy systems on identification and evaluation of soccer players' position is represented in this article. In other words, fuzzy logic, as an appropriate means, has been applied to study soccer player's personality traits and skills to figure out which position suits each individual best. Soccer experts are aware of the fact that a successful soccer player in any intended position must bear some specific characteristics. Using fuzzy logic, a model has been offered, called soccer player position identification. This model has some important features: First, the most appropriate position for each individual player can be identified. Second, this system offers some solutions to problems caused by the experimental and intuitive couches' ideas about player positioning which decreases the need for experts and professional couches. Third, this model overcomes the problems in the analysis of player positioning without the need for quantitative scales, and last but not least, this easy and interpretable method, applied to 264 soccer players' assessments have revealed that the designed fuzzy system is able to identify the qualities among players.
\end{abstract}

Index Terms - Fuzzy Logic, Interpretability, Soccer Players, Player position, Quantitative Scales

\section{INTRODUCTION}

Most parents like their children to experience success in a sport field. Some are more likely to see their child ren on professional levels as national or international champions. This interest is more toward the most popular sport worldwide, which is soccer. Identification process to participate in an organized practice schedule in soccer has been the is sue of concern for many years. The most important things are soccer aptitude identification and its application in appropriate situations.

First, the issue of player positioning in the soccer field will be analyzed, then experimental and scientific features and scales of each soccer player in his professional position will be identified and evaluated. Finally, its relationship with fuzzy logic and the application of this logic on finding the appropriate position for each individual as well as his performance assessment on that position will be offered.

Nowadays artificial intelligence has been used in many sciences, but in the field of soccer in [1], a nearest neighbor method tried to find soccer talent. This method is applicable but not interpretable. In another work, an expert fuzzy system is used to define the soccer goalkeeper quality [2]. In [3, 4] soccer positioning are divided into 5 groups. In some article the position of players is classified based on the possession of ball [5] and in $[6,7]$ the key characteristics needed to play in a certain position within soccer are studied.

Generally, there is no applicable scientific formula to distinguish soccer player's position; soccer coaches apply their experimental knowledge on positioning players. Identify the sport talents using a web oriented expert system with a fuzzy module and try to predict and plan the most suitable sports for the person who has taken the test [8].

This study applies fuzzy logic to create a model to analyze the quality of each player in all possible positions (11 different categories are considered in this study). Membership functions are the cores of this fuzzy model. Experts' knowledge is the basis of these functions and rules. An expert is the one who has gained a lot of knowledge by time. The aim of this research is to design a fuzzy model according to expert's knowledge on resolving problems of false positioning of the players as well as enhancing the accurate output regarding the issue.

The rest of paper is organized as follows: application of fuzzy approach in determining soccer players' position is described in section II. In section III briefly presents the fundamentals of fuzzy set and its operators. Research method is shown in section IV. Section V describes how the fuzzy model is designed. Section VI includes evaluation and results are given in section VII. Paper is concluded in section VIII.

\section{APPLICATION OF FUZZY APPROACH IN DETERMINING SOCCER PLAYERS' POSITION}

Place use of fuzzy systems is one of the fastest growing methodologies in systems engineering [9]. Fu zzy is in contrast with crisp logic. Fuzzy concepts like efficacy of each player in his position cannot be defined in any exact terms. There are no exact spatial or chronological te mporal defin itions for linguistic concepts. On the other hand, fuzzy logic is related to the definition of fuzzy set.

Mr. Lotfizade in "harmony principle" states that when a system becomes more complicated the ability of an individual to use exact statements decreases [10]; It is easily recognized that in solving real problems there is a need for intelligent systems to combine knowledge, techniques and methodologies obtained from various sources [11]. Ecological studies are known to be complex in nature [12]. Therefore fuzzy logic seems to solve the 
two mode problem $(0,1)$ in determining quality and performance (amount of goodness in different methods and compare their results) [13].

The theory of fuzzy sets provides a more realistic mathematical representation of the perception of truth than traditional, two valued logic and Boolean algebra. In the transition from crisp sets to fuzzy sets, the key element is membership functions [14].

As a result of complicated and intricate nature of position determination for soccer players, fuzzy logic can be suitable for such assessments. This logic offers a suitable means for the followings:

- Soccer player attributes selection

- The analysis of the amount of above mentioned attribute and its importance for each position as well

- Decision making by the couches

\section{FUNDAMENT ALS OF FUZZY SET AND OPERATORS}

The mathematics of fuzzy sets and fuzzy logic is discussed in detail in many books and articles [12, 14-16]. In this article, only certain basic aspects concerning the mathematics that underlie fuzzy logic are discussed. The minimal information needed to understand the construction method is provided here. The general illustrations for the fuzzy models are introduced later on.

\section{A. From crisp to fuzzy sets}

Let $U$ be a collection of objects $u$ which can be discrete or continuous. $U$ is called the universe of discourse and $u$ represents an element of $U$. A crisp subset $C$ in a universe $\mathrm{U}$ can be denoted in several ways like, in the discrete case, by enumeration of its elements: $\quad \mathrm{C}=\left\{\mathrm{u}_{1}, \mathrm{u}_{2}, \ldots, \mathrm{u}_{\mathrm{p}}\right\}$ with $\forall_{\mathrm{i}}: \mathrm{u}_{\mathrm{i}} \in$ U. Another way to utilize $\mathrm{C}$ (both in the discrete and the continuous case) is by using the characteristic function $\mathrm{X}_{\mathrm{f}}: \mathrm{U} \rightarrow\{0,1\}$ according to $\mathrm{X}_{\mathrm{f}}(\mathrm{u})=1$ if $u \in C$, and $X_{f}(u)=0$ if $u \notin C$. The latter type of definition can be generalized in order to define fuzzy sets. A fuzzy set $\mathrm{F}$ in a universe of discourse $\mathrm{U}$ is characterized by a membership function $\mu_{\mathrm{F}}$ which takes values in the interval $[0,1]$ namely, $\mu_{\mathrm{F}}: \mathrm{U} \rightarrow[0,1]$.

\section{B. Operators on fuzzy sets}

The Let $A$ and $B$ be two fuzzy sets in $U$ with membership functions $\mu_{A}$ and $\mu_{B}$, respectively. The fuzzy set resulting from operations of union, intersection, etc. of fuzzy sets are defined using their membership functions. Generally, several choices are possible:

Union: The membership function $\mu_{\mathrm{A} \cup \mathrm{B}}$ of the union $A \cup B$ can be defined by:

$$
\begin{aligned}
& \forall \mathrm{u}: \mu_{\mathrm{A} \cup \mathrm{B}}=\max \left\{\mu_{\mathrm{A}}(\mathrm{u}), \mu_{\mathrm{B}}(\mathrm{u})\right\} \\
& \text { Or } \forall \mathrm{u}: \mu_{\mathrm{A} \cup \mathrm{B}}=\mu_{\mathrm{A}}(\mathrm{u})+\mu_{\mathrm{B}}(\mathrm{u})-\mu_{\mathrm{A}}(\mathrm{u}) \mu_{\mathrm{B}}(\mathrm{u})
\end{aligned}
$$

Intersection: The membership function $\mu_{\mathrm{A} \cap \mathrm{B}}$ of the union for all $\mathrm{A} \cap \mathrm{B}$ can be defined by:

$$
\begin{aligned}
& \forall \mathrm{u}: \mu_{\mathrm{A} \cap \mathrm{B}}=\min \left\{\mu_{\mathrm{A}}(\mathrm{u}), \mu_{\mathrm{B}}(\mathrm{u})\right\} \\
& \text { Or } \forall \mathrm{u}: \mu_{\mathrm{A} \cap \mathrm{B}}=\mu_{\mathrm{A}}(\mathrm{u}) \mu_{\mathrm{B}}(\mathrm{u}) .
\end{aligned}
$$

Complement: The membership function of the complementary fuzzy set $A^{c}$ of $A$ is usually defined by:

$$
\forall \mathrm{u}: \mu_{\mathrm{A}^{\mathrm{c}}}=1-\mu_{\mathrm{A}}(\mathrm{u})
$$

\section{Linguistic Variables}

Fuzzy logic enables the modeling of expert knowledge. The key notion to do so is that of a linguistic variable (instead of a quantitative variable) which takes linguistic values (instead of numerical ones). For example, if the length is a linguistic variable, then its linguistic values could be one from the term set $\mathrm{T}($ length $)=\{$ short, tall $\}$ where each term in $\mathrm{T}$ (length) is characterized by a fuzzy set in the universe of discourse, here, e.g., $U=[110 \mathrm{~cm}$, $220 \mathrm{~cm}]$.

These linguistic values are characterized by fuzzy sets described by a membership function as shown in Fig. 1.

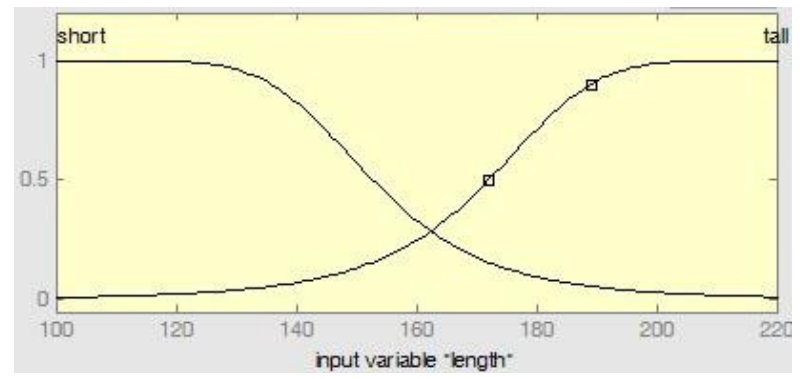

Fig. 1. Diagrammatic representation of the linguistic variable 'length' having linguistic values short and tall defined by a corresponding membership function that designed using MATLAB software.

\section{IF_THEN rules}

Fuzzy logic enables the formulation of prototypical linguistic rules of a fuzzy model that can easily be understood by experts where, at the same time, all kinds of mathematical details are hidden. To do so, knowledge is represented by fuzzy IF-THEN linguistic rules having the general form:$$
\text { B }
$$$$
\text { If } x_{1} \text { is } A_{1} \text { AND } x_{2} \text { is } A_{2} \ldots \text { AND } x_{m} \text { is } A_{m} \text { THEN } y \text { is }
$$

Where $x_{1}, \ldots, x_{m}$ are linguistic input variables with linguistic values $A_{1}, \ldots, A_{m}$, respectively and $y$ is the linguistic output variable with linguistic value $B$.

An example of the relevant fuzzy rules could be:

$>$ IF dribbling is strong AND shooting is strong THEN the player (is) level6 for Forward.

$>$ IF dribbling is weak AND shooting is strong THEN the player (is) level4 for Forward.

\section{E. Architecture of fuzzy systems}

Fuzzy inference systems usually implement a crisp input-output mapping consisting of basically four units, namely:

A Fuzzifier transforming crisp inputs into the fuzzy domain, a rule base of fuzzy IF-THEN rules, an inference engine implementing fuzzy reasoning by combining the fuzzified input with the rules of the rule base, a Defuzzifier transforming the fuzzy output of the inference engine to a crisp value (Fig. 2). 


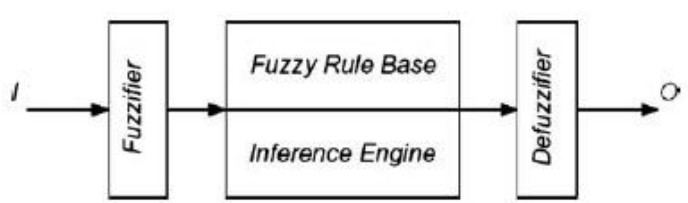

Fig. 2. Building blocks of a Fuzzy Inference System.

In some practical systems, the Fuzzifier or the Defuzzifier may be absent.

\section{F. Fuzzy reasoning}

Probably the hardest part to understand is the precise way that fuzzy reasoning can be implemented. An extensive discussion of this topic is beyond the scope of this paper, so the basic idea is just presented here. Classical logic is our starting point using the classical reasoning prototype 'modus ponens':

Given fact " $\mathrm{x}$ is $\mathrm{A}$ " and rule "IF $\mathrm{x}$ is $\mathrm{A}$, THEN $\mathrm{y}$ is $\mathrm{B}$ ', resulting " $\mathrm{y}$ is $\mathrm{B}$ '.

Applying fuzzy reasoning, classical modus ponens can be generalized to an 'approximate reasoning' scheme of type:

Given fact " $\mathrm{x}$ is $\mathrm{A}$ '," and rule " $\mathrm{IF} \mathrm{x}$ is $\mathrm{A}$, THEN $\mathrm{y}$ is $\mathrm{B}$ ', resulting " $\mathrm{y}$ is $\mathrm{B}^{\prime}$ ',

Here, the assumption made is that the closer $\mathrm{A}^{\prime}$ to $\mathrm{A}$, the closer will be $\mathrm{B}^{\prime}$ to $\mathrm{B}$. It turns out that especial combinations of operations on fuzzy sets like ' $\max -\mathrm{min}$ ' and 'max-product' composition can fulfill this requirement. The complete fuzzy reasoning in a FS can be set up as follows:

(1) The fuzzification module calculates the 'firing rate' (or degree of fulfillment) of each rule by taking into account the similarity between the actual input $A^{\prime}$ defined by membership function $A^{\prime}(x)$ and in case of a crisp input $X_{p}$ defined by the value $\mu_{A}\left(X_{p}\right)$ and the input $A$ of each rule defined by membership function $\mu_{\mathrm{A}}(\mathrm{X})$.

(2) Using the firing rates calculation, the inference engine determines the fuzzy output $\mathrm{B}^{\prime}$ for each rule, defined by membership function $\mu_{\mathrm{B}^{\prime}}(\mathrm{y})$.

(3) The inference engine combines all fuzzy outputs B' into one overall fuzzy output defined by membership function $\mu(\mathrm{y})$

(4) The defuzzification module calculates the crisp output $y_{p}$ using a defuzzification operation like, center of gravity (area)'.

For more details on fuzzy systems, their construction and corresponding reasoning schemes, one can refer to the most popular systems like Mamdani [17] and Takagi Sugeno [18] fuzzy models.

\section{RESEARCH METHOD}

First of all, the different positions in soccer game should be identified! Then, the players should be classified based on the requirements for these positions. Soccer players are positioned in the following classes [12] :

(1) Goalkeeper
(2) Sweeper

(3) Wing backs

(4) Right back and Left back (side defender)

(5) Defensive midfielder

(6) Wingers

(7) Wide midfielder

(8) Center midfielder

(9) Attacking midfielder

(10) Secondary striker

(11) Forward

On the other hand, each soccer player may have the following properties:

(1) Physical properties [19-21]:

a. speed, b. agility, c. ju mping ability, d. acceleration, e. height, f. physical strength, g. vigor

(2) Mental properties [19, 22]:

a. the ability to read game, b. calmness, c. creativity, d. boldness, e. confidence and decision making, $f$. influence on other team members (leadership)

(3) Technical properties [19]:

a. the ability to end, b. passing, c. shooting, d. heading ability, e. tackling, f. carrying the ball, g. single play, h. dribbling, i. crossing, j. backing, k. attacking play

For positioning players the following properties should be considered:

Properties of a sweeper: 22].

Play reading, calmness, leadership, agility, speed [21,

Properties of Wing backs:

Backing, boldness, being tall, physical strength, heading ability $[19,20]$.

Properties of Right and left backs:

Speed, acceleration, tackling, Crossing, agility [21, 22].

Properties of Defensive midfielders:

Attacking play, physical strength, shooting, backing, play reading, vigor $[21,22]$.

Properties of center midfielders:

Vigor, passing, shooting, creativity, confidence and decision making, leadership [19].

Properties of wingers:

Vigor, crossing, passing, tackling, speed, carrying the ball [19, 20].

Properties of attacking midfielders:

Creative, carrying the ball, passing, calmness, dribbling, shooting [19, 20, 22].

Properties of wide midfielders:

Crossing, carrying the ball, passing, dribbling, speed, acceleration, agility, vigor [19, 21].

Properties of secondary strikers:

Being tall, the ability of single play, passing, agility, physical strength, heading ability [19].

Properties of forward:

ability to end, shooting, heading ability, speed, calmness, dribbling, creativity [19, 22].

\section{DESIGNING THE FUZZY MODEL}

A fuzzy system in accordance with these ten positions has been designed (the 11th position is goalkeeper). Be 
able to easily change and update properties and parameters of each position as well as their efficacies, all positions are not placed in one system. Moreover, normally there are 24 attributes for each player; so if one fuzzy system is applied on each input, there would be 1677216 rules which in turn leads to a complicated system, thus the system would not be described properly and interpretably.

Here, a fuzzy model for right and left backs is going to be discussed. As previously mentioned the attributes of a qualified right or left back include speed, acceleration, tackling, crossing and agility.

Now, we should relate fuzzy sets (linguistic variables) to input (Table $1 \&$ Fig. 3).

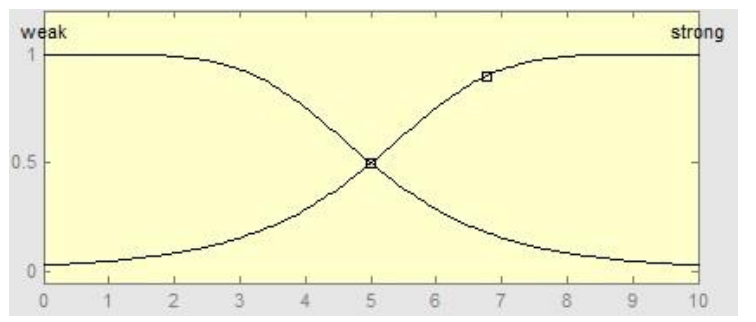

Fig. 3. Membership function of the linguistic variables

Table 1. Linguistic variables of input

\begin{tabular}{|c|c|}
\hline Input(property) & Linguistic variables \\
\hline Speed & strong-weak \\
\hline Acceleration & strong-weak \\
\hline Tackle & strong-weak \\
\hline Crossing & strong-weak \\
\hline Agility & strong-weak \\
\hline
\end{tabular}

The reason for applying two linguistic variables on each input is to obtain interpretable rules and avoid large number of rules as well.

Obtaining attributes, it has been found that attributes have not been prioritized. Therefore, it can be implied that each property plays an equal role in determining the quality of each position.

Since there are five attributes regarding right and left back position; in total, there would be 32 rules. The applicability of the combination of these rules is necessary to obtain any output. Assigning 6 fuzzy sets or linguistic variables to output and applying statistics we can attain rules (Fig. 4).

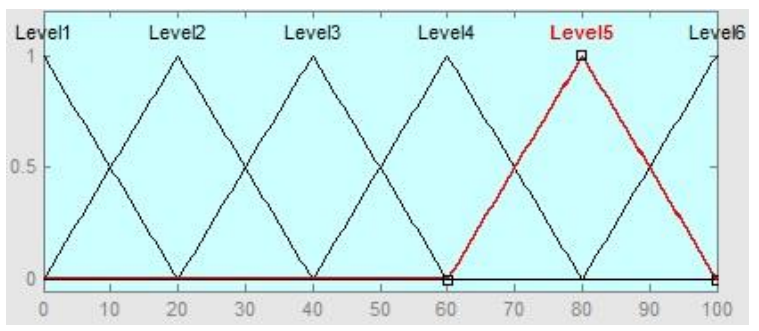

Fig. 4. Linguistic variables of final output

According to table 2, there would be 832 rules obtained from 10 fuzzy systems which are highly interpretable. System offers the results to its users more rapidly and accurately.
Table 2. The number of principles according to properties (input).

\begin{tabular}{|c|c|c|}
\hline Position & No. of attributes & No. of rules \\
\hline Sweepers & 5 & 32 \\
\hline Wingbacks & 6 & 64 \\
\hline Right backs & 5 & 32 \\
\hline Left backs & 6 & 64 \\
\hline Center midfielder & 6 & 64 \\
\hline Wingers & 6 & 64 \\
\hline Attacking midfielder & 6 & 64 \\
\hline Wide midfielder & 8 & 256 \\
\hline Secondary strikers & 6 & 64 \\
\hline Forward & 7 & 128 \\
\hline Total & 24 & 832 \\
\hline
\end{tabular}

Calculations show that for each output variable there would be a specific number of rules. (Table 3 )

Table 3. Various principle of a side defender

\begin{tabular}{|c|c|c|}
\hline Rule sample & $\begin{array}{c}\text { No. of } \\
\text { rules }\end{array}$ & $\begin{array}{c}\text { Linguistic } \\
\text { variables }\end{array}$ \\
\hline strong-strong-strong-strong-strong & 1 & Level1 \\
\hline strong-strong-strong-strong-weak & 5 & Level2 \\
\hline strong-strong-strong-weak-weak & 10 & Level3 \\
\hline strong-strong-weak-weak-weak & 10 & Level4 \\
\hline weak-strong- weak-weak-weak & 5 & Level5 \\
\hline weak-weak-weak-weak-weak & 1 & Level6 \\
\hline
\end{tabular}

This is true for all attributes except for " being tall". Being tall is assigned in the range of (100-220) centimeters. The users, mostly soccer couches, are able to evaluate the efficacy of each individual player in any assigned position by applying input to the system. For all 23 input parameters an amount of 0-100 will be as signed. Moreover, it may be possible to use terms strong or weak instead of numerical values. Then, for example, for "being tall" input the height of players will be inserted into the system (the linguistic terms tall or short are also applicable). Lastly, the fuzzy model will show the players' skills in all 10 positions.

Using MATLAB software, fuzzy model for side defender has been designed. It is illustrated in fig. 5 .

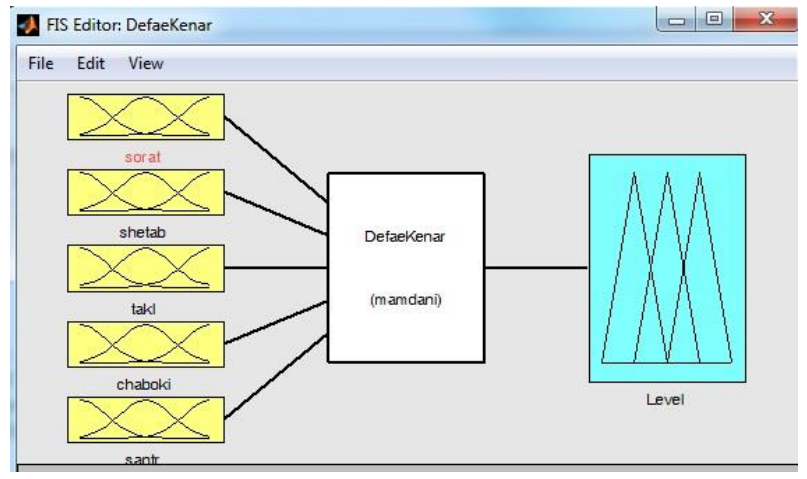

Fig. 5. schematic model of right and left side defender fuzzy system using MATLAB software. 
For example, according to table 3 a player has obtained the following scores on basic properties as a right and left back (Table 4).

Table 4. Calculating a player's talent as a right and left back

\begin{tabular}{|c|c|}
\hline Properties & Player \\
\hline Player speed & 70 \\
\hline Acceleration & 56 \\
\hline Tackle & 43 \\
\hline Agility & 92 \\
\hline Crossing & 77 \\
\hline The score of player as a side defender & 61.6 \\
\hline
\end{tabular}

The results obtained according to table 3 input are illustrated in fig. 6 using MATLAB software.

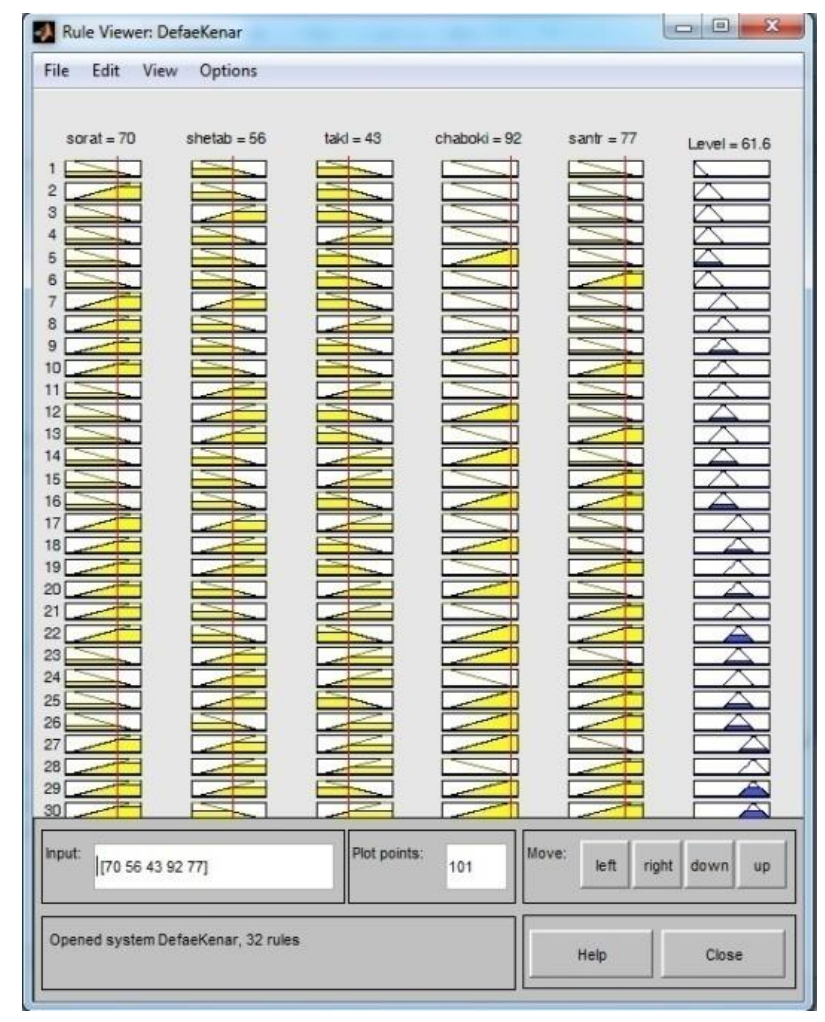

Fig. 6. Illustration of final output of player using MATLAB software.

All 24 inputs are inserted into all 10 fuzzy systems. For every position a score showing the ability of a player on the position has been obtained. Higher scores show higher quality of the individual player for that specific position.

\section{IMPLEMENT ATION AND EVALUATION}

A Submit Table 5 illustrates a fuzzy system to find talents of soccer players. It shows a high performance of $91 \%$ for the fuzzy system of accurate talent identification.

This system has been tested in three soccer schools in Shiraz as an independent program. 5 university professors, experts on soccer have analyzed the system. The results are as follows:

\section{A. Evaluation 1}

A sample group of 264 soccer players aged 18-31 have been selected. The scores of each individual player on all 10 positions have been obtained at a scale of 100 . Then, 5 university lecturers (experts) analyzed the scores.

Experts were asked to prioritize appropriate positions for every individual player. (Experts were not informed of current position of players). In the case that any individual player's current position is among the first three positions offered by the system, it can be concluded that output information is accurate. Otherwise it is not reliable. Table 5 illustrates the results. Fuzzy system by $91 \%$ accurate outcome shows a good performance.

Table 5. The comparison of comments given by five experts based on fuzzy system for analysis \# 1.

\begin{tabular}{|c|c|c|c|}
\hline rate & Fuzzy system/expert & \#Accurate outcome & Percentage \\
\hline 1 & Expert 1 & 248 & $94 \%$ \\
\hline $\mathbf{2}$ & Fuzzy Approach & $\mathbf{2 4 0}$ & $\mathbf{9 1 \%}$ \\
\hline 3 & Expert 2 & 204 & $77 \%$ \\
\hline 4 & Expert 3 & 188 & $71 \%$ \\
\hline 5 & Expert 4 & 172 & $65 \%$ \\
\hline 6 & Expert 5 & 168 & $63 \%$ \\
\hline
\end{tabular}

\section{B. Evaluation 2}

An expert was asked to describe fuzzy Approach outcomes for another set of 42 soccer players. There will be five possible descriptions: totally agree, basically agree, none specified, basically disagree, strongly disagree.

The results have been illustrated in table 6 .

Table 6. An expert description of fuzzy Approach

\begin{tabular}{|c|c|}
\hline Comment & Number \\
\hline Totally agree & 35 \\
\hline Basically agree & 2 \\
\hline None specified & 4 \\
\hline Basically disagree & 1 \\
\hline
\end{tabular}

Identical high resolution PDF file with all fonts embedded. Use Adobe Acrobat Distiller and choose the job option Press-Optimized.) Please make sure you do not submit more than one version of any item.

\section{CONCLUSION}

Soccer coaches do not follow a specific formula on positioning players and they merely apply their experience; therefore, coaches may disagree on choosing an appropriate person on a position. In a fuzzy model proposed by this research, every individual player is being evaluated based on his general properties and performance. Each player gains a score in the range of $(0$ to 100), so this method is more efficient in comparison to traditional methods. 
This model has some advantages: First, identify the most appropriate position for each individual player. Second, this system offers some solutions that decrease the need for experts and professional couches. Third, this model overcomes the problems in the analysis of player positioning without the need for quantitative scales, and last but not least although this method is proposed for the first time but the results indicate the high accuracy of the method to determine the best position for each player.

\section{REFERENCES}

[1] Bazmara, M. and S. Jafari, K Nearest Neighbor Algorithm for Finding Soccer Talent. Journal of Basic and Applied Scientific Research, 2013. 3(4): p. 981-986.

[2] Bazmara, M. and S. Jafari, A Fuzzy expert system for goalkeeper quality recognition. International Journal of Computer Science Issues, 2012. 9(5): p. 318-322.

[3] Hughes, M.D., et al., Moneyball and soccer-an analysis of the key performance indicators of elite male soccer players by position. JOURNAL OF HUMAN SPORT \& EXERCISE, 2012. 7(2): p. 402-412.

[4] Wiemeyer, J., Who should play in which position in soccer? Empirical evidence and unconventional modelling. International Journal of Performance Analysis in Sport, 2003. 3(1): p. 1-18.

[5] Van Lingen, B., Coaching soccer: The official coaching book of the Dutch Soccer Association. 1998: Reedswain Inc.

[6] Cook, M., Soccer coaching and team management. 1982: EP Pub.

[7] SMITH, M., Success in Football. 1993: Butler and Tanner.

[8] Papić, V., N. Rogulj, and V. Pleština, Identification of sport talents using a web-oriented expert system with a fuzzy module. Expert Systems with Applications, 2009. 36(5): p. 8830-8838.

[9] Grint, K., Fuzzy management: Contemporary ideas and practices at work. 1997: Oxford University Press Oxford.

[10] Zadeh, L.A., Fuzzy sets. Information and control, 1965. 8(3): p. 338-353.

[11] Zadeh, L.A., Outline of a new approach to the analysis of complex systems and decision processes. Systems, Man and Cybernetics, IEEE Transactions on, 1973(1): p. 28-44.

[12] Jang, J.-S.R., C.-T. Sun, and E. Mizutani, Neuro-fuzzy and soft computing-a computational approach to learning and machine intelligence [Book Review]. Automatic Control, IEEE Transactions on, 1997. 42(10): p. 1482-1484.

[13] Silvert, W., Ecological impact classification with fuzzy sets. Ecological Modelling, 1997. 96(1): p. 1-10.

[14] Zimmermann, H.J.r., Fuzzy set theory-and its applications. 2001: Springer.

[15] Lee, C.-C., Fuzzy logic in control systems: fuzzy logic controller. Systems, Man and Cybernetics, IEEE Transactions on, 1990. 20(2): p. 404-418.

[16] Ruspini, E.H., P.P. Bonissone, and W. Pedrycz, Handbook of fuzzy computation. 1998: Institute of Phy sics Pub.

[17] Mamdani, E.H. and B.R. Gaines, Fuzzy Reasonings and Its Applications. 1981: Academic Press, Inc.

[18] Takagi, T. and M. Sugeno, Fuzzy identification of systems and its applications to modeling and control. Systems, Man and Cybernetics, IEEE Transactions on, 1985(1): p. 116132.

[19] Duraskovic, R., A. Joksimovic, and S. Joksimovic, Weight-height parameters of the 2002 world football championship participants. Facta universitatis-series: Physical Education and Sport, 2004. 2(1): p. 13-24.

[20] McIntyre, M.C. and M. Hall, Physiological profile in relation to playing position of elite college Gaelic footballers. British Journal of Sports Medicine, 2005. 39(5): p. 264-266.

[21] Ostojic, S.M., Physical and phy siological characteristics of elite Serbian soccer players. Facta universitatis-series: Physical Education and Sport, 2000. 1(7): p. 23-29.

[22] Raven, P.B., et al., A physiological evaluation of professional soccer players. British Journal of Sports Medicine, 1976. 10(4): p. 209-216.

\section{Author's Profiles}

Mohammad Bazmara was born in 1987, he received his M.Sc. degree in artificial intelligence from the School of Electrical and Computer Engineering, Shiraz University, Shiraz, Iran, in 2013. His research interests include fuzzy logic, statistical pattern recognition, evolutionary algorithms and machine learning.

How to cite this paper: Mohammad B azmara,"A Novel Fuzzy Approach for Determining Best Position of Soccer Players", International Journal of Intelligent Systems and Applications(IJISA), vol.6, no.9, pp.62-67, 2014. DOI: 10.5815/ijisa.2014.09.08 